\title{
An Analysis of the Role of Higher Education Opportunity Expansion in Social Stratification
}

\section{Lulu Ma* Cuilan Zhao}

Qingdao University, Qingdao, Shandong, 266071, China

\section{ARTICLE INFO}

Article history

Received: 29 September 2020

Revised: 6 October 2020

Accepted: 9 October 2020

Published Online: 16 October 2020

Keywords:

Higher education

Social stratification

Social mobility

Educational equity

\begin{abstract}
With higher education entering the public's vision, the expansion of higher education opportunities has gradually become a hot topic. The lower class is eager to achieve class mobility through this opportunity, while the upper class firmly grasps the few high-quality places in higher education. What role will the expansion of higher education opportunities plays in the overall social stratification? This paper discusses the impact of the expansion of higher education opportunities on social stratification from the upper class and the lower class.
\end{abstract}

opportunities provides more educational opportunities for children with disadvantaged family backgrounds, thereby reducing social inequality, or mainly benefiting children from superior families, thus widening social inequality (Mare, 1980; Shavit and Blossfeld, 1993) ${ }^{[2-3]}$. Social mobility plays an important role in the development of the whole society. His powerful role in promoting the development of human body and mind and socialization makes it more and more concerned by the society.

In real life, we can see that with the transformation of social and economic system and the popularization of education, education plays little role in social mobility. "Higher Education Popularization" was first proposed by Terro (Trow, 1973). According to the difference be-

*Corresponding Author:

Lulu Ma,

Qingdao University, Qingdao, Shandong, 266071, China;

E-mail:940466022@qq.com. 
tween gross enrolment ratio, he divided the development process of higher education into three stages: elite higher education stage, popular higher education stage and universal higher education stage. Since the founding of New China, China has entered the stage of popular higher education from the stage of elite higher education, the number of people who can enter universities every year has increased year by year, and all social strata are flowing with each other.

\section{The Role Played by the Expansion of Higher Education Opportunities in Social Stratification}

The diversion of higher education refers to the activities of the higher education system to bring college students into different levels and different types of colleges and universities in a planned, hierarchical and proportional manner according to the needs of the society and the wishes and conditions of the students themselves, in order to better accept the corresponding professional education and train the senior specialized talents needed for social development ${ }^{[4]}$. The so-called higher education system can also be said to be the current college entrance examination diversion system. The college entrance examination is a selective examination, and the schools entered are divided from high to low according to the final college entrance examination results. Although this division mechanism maintains the equality of face, it continues the inequality behind it. The expansion of higher education does bring more educational opportunities for the lower class, but at present, China's higher education presents a significant "stratification" characteristics. Students from different family backgrounds have significant quality differences in acceptable primary and secondary education. Because this "inequality at the starting point" will directly lead to different quantity and quality of higher education opportunities and resources, the lower class enters this "low score" admission university, which makes it difficult for them to which makes it difficult for them to achieve social mobility and get rid of the present class identity.

\subsection{Influence on the Upper Class}

The upper class has the advantage of educational resources, mutual use, layer by layer intertwined to form a huge network of interests, mutual support, mutual benefit this is called "elite replication". The dominant groups of the economic, political and cultural capital of education always try everything possible to pass on their own advantages and let their children receive better elite education in order to smoothly integrate into the upper circle and continue to maintain the position of the whole family in the upper class.

China has always been a relationship-based society, which Fei Xiaotong mentioned in Native China. The socalled relationship standard is centered on interpersonal communication. It has to be said that the existence of "face", "human feelings" and "relationship" in China is the destruction of the rules. "When I look at the humanities, I am surprised that none of these branches of knowledge can be separated from the operation of power...... All this is closely connected with the power mechanism... This power forces you to speak. Otherwise, you are not only treated as "wrong ", but even as "liar" "[] . In the course of the whole social game, the upper elite that mastered the economic and political discourse power desperately maintain their position and reject and suppress the lower class. In this regard, even if the opportunities for higher education expand, what is the relationship between the admission places of those famous universities and the lower class? It is not ruled out that a small number of children of the lower class pass the examination to realize social mobility and enter the upper class, but this situation is minimal. In addition, the upper class not only occupies cultural capital, but also has unparalleled political capital and cultural capital. The power behind these two kinds of capital can not be realized through the efforts of a generation.

\subsection{Influence on the Lower Class}

As Solomon (Lewis C. Solomon) said:" Providing quality education is often more important than providing a large number of low-quality educations, especially for developing countries. ${ }^{,[6]}$ The large expansion of higher education opportunities can easily lead to a decline in quality of higher educations. Teachers can not keep up with the conditions, basic equipment is not up to standard, even so schools in response to the national call will still ignore their own conditions and large-scale enrollment. However, most of this large expansion exists in general colleges and local colleges, and the number of students admitted to so-called famous universities is basically unchanged. It is inconceivable that lower-class children will be "screened" thought examinations to ordinary colleges and universities and eager to achieve social mobility after graduation into the upper class. Because the upper class they know more about using the superior resources around them, firmly grasp their own interests, and set up a barrier with the lower class to prevent the lower class of crossing.

Our theory of differentiation and stratification within higher education in china (Raftery and Hout,1993) provides new empirical evidence for maximizing mainte- 
nance of educational inequality. According to the theory, the inequality of educational opportunities is maintained to the maximum extent, which means that the influence of family background on education at all levels in modern society is generally unchanged, and further educational expansion is likely to increase the access of vulnerable groups only when the enrolment of dominant groups has reached near saturation level ${ }^{[7]}$. This theory shows that the expansion of higher education opportunities is beneficial to the lower class. Although the upper class takes advantage of its own advantages to seize the best educational resources and go deep into the top universities, the expanded educational opportunities can still bring benefits to the lower class. The lower class gradually changed from nine years of compulsory education to "sixteen years of education" and from junior high school students to "college students ", which has to be said to be a great change.

For the lower class, education is the only way to change class and realize class mobility. Studies in recent years have shown that the proportion of lower-class children in key schools has decreased, the situation of rural drop-out has increased, and the opportunities for lower-class children to enter famous universities have been reduced, all of which indicate that the role of education in promoting lower-class mobility is becoming smaller and smaller, and the social stratification function of rural education is gradually weakening. With the development of social politics and economy, the attention of people at all levels of society begins to change from material level to spiritual level, and education has become more and more the object of attention. People expect their children to obtain social capital through education. Social mobility is realized, especially for the bottom people. However, because of the limited educational resources in the countryside, if the lower classes find that the educational expenses they invest do not meet their expected educational results, they will immediately stop the investment of educational capital and cut off the children's desire to continue their studies.

When we see that the opportunities for higher education are increasing year by year, the people of the lower class are secretly glad that they are so lucky to enter the university to study, but they do not know that the equality of opportunity is actually formal equality. Who is the person that formulates the policy of higher education expansion? Is the upper class, is the master of the voice of the social elite. The so-called expansion of access to higher education is only a means of maintaining social order. As our country enters the aging stage of population, the population labor force is short, and the open population fertility policy makes the lower class "poorer and poorer ", which will further increase the gap between the social strata. The social mobility function of education is weakened or even ineffective, and the lower class will always be in the lower class and serve the upper class.

\section{Summary and Discussion}

In modern society, education plays an increasingly important role in the acquisition of individual social status and social mobility. Bourdieu pointed out :" the most hidden and special function of the education system is to conceal its objective function, that is, to conceal the objective truth of its relationship with the structure of class relations .${ }^{,[8]}$ Many domestic scholars also believe that parents with higher education usually provide good education for their children, which leads to the circulation of quality education in the upper class, thus forming isolation mechanism and hindering social mobility. Social reproduction hinders social mobility. Social reproduction can be said that the upper class of social advantages continues to firmly grasp all kinds of opportunities, continue to strengthen their economic capital, and then separate their social capital from the lower circle, and only flow in the upper circle. This makes their own advantages more prominent, making economic, cultural and other reproduction.

However, this theory of social reproduction is not absolute. In a society with open characteristics, a person does not determine the development trend of his life because of his existing social hierarchy. He can change his destiny with his own efforts. After all, the disadvantaged lower class has the opportunity to contact higher education and hope to change class thought education. This attempt to achieve social class mobility through education is also a functional point of view. Functionalism holds that the level of skills acquired by individuals through education is the key to social stratification. After entering society, people can base themselves on and realize social class mobility through the acquired technical level. Although the expansion of higher education opportunities has not changed the social stratum, it also has a certain impact on the social stratum and promotes the flow between the social strata, which is already very difficult in today's society.

\section{References}

[1] McCarthy Institute. China University Student Employment Report [M].2010 Beijing:social Sciences Literature Press ,2010.(in Chinese)

[2] Mare, Robert D.1980."Social Backgrounds and Educational Continuation Decisions." Journal of American Statistical Association 75:295-305. 
[3] Shavit, Yossi and Hans-Peter Blossfeld.1993.Persistent Inequality.Boulder,CO:Westview.

[4] Dong Zefang, Peng Yongjun. [J]. Promoting Social Effective Differentiation and Integration by Reasonable Divergence of Higher Education Higher Education Research,2012,33(08):29-33.(in Chinese)

[5] Michel Foucault,Politics,Philosophy,Culture,New York:Vintage Books, 1979:106.

[6] SOLMON L C.Quality of Education and Economic Growth[J]. Economic of Education Re- view,1985,4:273-290.

[7] Raftery,Adrian E.and Michiel Hout.1993."Maximally Maintained Inequality:Expansion, Reform, and Opportunity in lrish Education:1921-1975." Sociolly of Education 66(1):41-62.

[8] P Bourdieu, J,C·Paslon. Essentials of the Theory of Reproduction-Specific Education System [Translated M]. Jing Ke Chao, Beijing: Commercial Press ,2004. (in Chinese) 